\title{
Low-fat yogurt alleviates the pro-inflammatory cytokine IL-1 $\beta$-induced intestinal epithelial barrier dysfunction
}

\author{
Zhengyuan Zhai, ${ }^{1,2}$ Jiaojiao Wang, ${ }^{2}$ Baozhu Huang, ${ }^{1,3}$ and Sheng Yin ${ }^{1,3 *}$ \\ ${ }^{1}$ Beijing Advanced Innovation Center for Food Nutrition and Human Health, Beijing Technology and Business University, Beijing 100048, \\ PR China \\ ${ }^{2}$ Beijing Advanced Innovation Center for Food Nutrition and Human Health, College of Food Science and Nutritional Engineering, \\ China Agricultural University, Beijing 100083, PR China \\ ${ }^{3}$ Beijing Engineering and Technology Research Center of Food Additives, Beijing Technology and Business University, Beijing 100048, PR China
}

\section{ABSTRACT}

Yogurt is a source of bioactive compounds and probiotic microorganisms that modify immunity and metabolism to benefit human health beyond nutrition. In this study, we examined the capacity of yogurt to prevent epithelial barrier disruption in vitro. Different preparations of yogurt were added apically to Caco-2 monolayers before IL-1 $\beta$ exposure. Dulbecco's modified Eagle medium containing 25\% (vol/vol) low-fat yogurt prevented cytokine-induced transepithelial resistance reduction and increases to paracellular permeability measured with fluorescein isothiocyanate-dextran (4 $\mathrm{kDa}$ ), whereas nonfat yogurt was unable to decrease paracellular permeability to fluorescein isothiocyanatedextran. Moreover, the concentration of IL- 8 in low-fatyogurt-treated inflamed cells was decreased to $252.40 \pm$ $27.24 \mathrm{pg} / \mathrm{mL}$, which was lower than that of untreated, inflamed cells $(407.20 \pm 50.05 \mathrm{pg} / \mathrm{mL})$, further indicating the anti-inflammatory roles of low-fat yogurt. The low-fat yogurt was able to downregulate the transcription of myosin light-chain kinase $(M L C K)$ gene, but upregulate the expression of tight junction protein $\mathrm{ZO}-1$ (TJP1). These findings indicate that low-fat yogurt can maintain intestinal barrier integrity better than nonfat yogurt after pro-inflammatory cytokine exposure.

Key words: low-fat yogurt, intestinal barrier, antiinflammation, IL-8, $M L C K$

\section{INTRODUCTION}

Intestinal epithelial cells form a physical and biochemical barrier that segregates host tissue and luminal contents, such as digestive enzymes, degraded food products, and microbes to maintain intestinal homeo-

Received June 17, 2018.

Accepted October 11, 2018.

*Corresponding author: yinsheng@btbu.edu.cn stasis (Peterson and Artis, 2014; Luissint et al., 2016). Disruption of intestinal barrier can lead to loss of immune tolerance to pathogens and foodborne antigens, and result in an inappropriate inflammatory response (Citi, 2018), as is thought to occur in the inflammatory bowel diseases (IBD), ulcerative colitis, and Crohn's disease (Xavier and Podolsky, 2007; Chichlowski and Hale, 2008; Knight et al., 2008; Ohland and MacNaughton, 2010). Inflammatory bowel disease presently has no known cure; anti-inflammatory drugs, steroids or anti-tumor necrosis factor, and biologics can only maintain the epithelial barrier and reduce the symptoms associated with IBD (Suenaert et al., 2002; Talley et al., 2011). Although pharmacological approaches can provide sustained benefits, they are costly and can result in unwanted severe side effects. Therefore, alternative approaches such as nutrition-based strategies to manage inflammatory flare-ups could complement and support current clinical practices.

Yogurt is important for a balanced diet and a good source of AA, fatty acids, carbohydrates, vitamins, and minerals. Yogurt is also a source of bioactive compounds and probiotic microorganisms that modify immunity and metabolism to benefit human health beyond nutrition (Meydani and Ha, 2000). Epidemiological studies have concluded that yogurt consumption has the potential to improve intestinal health, ameliorate lactose intolerance, prevent constipation and diarrheal diseases, and reduce the risks of colon cancer and IBD (Adolfsson et al., 2004; Astrup, 2014). Yogurt and its associated probiotics may also improve intestinal barrier function by maintaining the expression of tight junction proteins and prevent intestinal inflammation and tissue damage (Putt et al., 2017). Consumption of yogurt with Lactobacillus bulgaricus strains and Streptococcus thermophilus strains decreased mortality rate and prevented intestinal inflammation and tissue damage in mice with trinitrobenzene sulfonic acid (TNBS)-induced intestinal inflammation (Chaves et al., 2011). In addition, yogurt without added pro- 
biotic strains inhibited TNBS-induced colitis in mice, increased the number of IgA-producing cells, and decreased CD8 + T cells 2 wk after TNBS administration (Gobbato et al., 2008). Yogurt consumption improved postprandial metabolism and biomarkers of metabolic endotoxemia in healthy premenopausal women (Pei et al., 2018). These results strongly indicate that bioactive components in yogurt, such as peptide, oligosaccharide, exopolysaccharide, and short-chain fatty acids may play an important role in maintaining gut barrier function and anti-inflammation. However, only a few studies have addressed the direct effect of yogurt on intestinal barrier function (Southcott et al., 2008; Putt et al., 2017; Usui et al., 2018).

In this study, we employed an in vitro pro-inflammatory cytokine induced, inflamed Caco-2 model to investigate the effects of yogurt made from bovine milk on preventing epithelial barrier dysfunction. Transepithelial electrical resistance (TER), paracellular permeability, and cytokine production were measured after IL-1 $\beta$ treatment. The expression of myosin light-chain kinase $(M L C K)$ and tight junction genes in yogurttreated Caco-2 cells was determined by quantitative reverse-transcription PCR (RT-qPCR).

\section{MATERIALS AND METHODS}

\section{Yogurt Sample Preparation}

Low-fat UHT bovine milk was purchased from San Yuan Foods Company (Beijing, China) through a local distributor. The nutritional composition for low-fat UHT milk is shown in Supplemental Table S1 (https: //doi.org/10.3168/jds.2018-15226). Skim milk was prepared using a rapid bovine milk fat separation method (Luna et al., 2005). Forty milliliters of low-fat UHT milk was centrifuged at $18,000 \times g$ for $30 \mathrm{~min}$ at $25^{\circ} \mathrm{C}$. The fat layer was removed and the rest of the fraction was centrifuged at $18,000 \times g$ for $30 \mathrm{~min}$ at $25^{\circ} \mathrm{C}$ again to further separate the milk fat. Protein of low-fat UHT milk and skim milk was determined via Kjeldahl nitrogen determination to confirm that the protein content was not significantly changed after milk fat separation (Horwitz, 1980). The yogurt was produced by inoculating low-fat UHT milk or skim milk with Yo-Flex YF-L812 (Chr. Hansen, Hoersholm, Denmark) composed of Streptococcus thermophilus and Lactobacillus delbrueckii ssp. bulgaricus according to the producer's recommendation followed by incubation at $42 \pm 1^{\circ} \mathrm{C}$. The fermentation was stopped when $\mathrm{pH}$ reached 4.6, and low-fat yogurt or nonfat yogurt was cooled down to $4^{\circ} \mathrm{C}$. The fat of the yogurt was extracted according to the Rose-Gottlieb method (Horwitz, 2000) and expressed in grams of fat per $100 \mathrm{~g}$ of the sample.
Fatty acid composition was determined with methylation method and GC as described previously (Trigueros and Sendra, 2015). These yogurts were diluted to $25 \%$ (vol/vol) with Dulbecco's modified Eagle medium (DMEM), centrifuged at $10,000 \times g$ for $10 \mathrm{~min}$ at $4^{\circ} \mathrm{C}$, and then adjusted to $\mathrm{pH}$ 7.4. The supernatant was collected and filtered through $0.22-\mu \mathrm{m}$ filters (Millipore, Bedford, MA).

\section{Epithelial Cell Culture and Cytokine Stimulation}

The human intestinal Caco-2 cells ATCC HTB-37 purchased from American Type Cell Culture (Rockville, MD) were cultured in high glucose DMEM, $10 \%$ fetal bovine serum, $1 \mathrm{~m} M$ sodium pyruvate, $0.1 \mathrm{~m} M$ NEAA, $2 \mathrm{~m} M$ GlutaMax, and $1 \% \mathrm{vol} / \mathrm{vol}$ penicillin/ streptomycin at $37^{\circ} \mathrm{C}$ in $5 \% \mathrm{CO}_{2}$ (all reagents from Gibco, Life Technologies, Carlsbad, CA). To form a monolayer, Caco-2 cells were seeded on polycarbonate membranes in Transwell inserts $(6.5 \mathrm{~mm}, 0.4 \mu \mathrm{m}$ pore size, 24 wells; catalog no. 3413, Corning Inc., Corning, NY) at a density of $1 \times 10^{4}$ cells $/ \mathrm{cm}$. After at least 21 d, TER was measured with an epithelial voltohmmeter (World Precision Instruments, Sarasota, FL) equipped with STX-2 "chopstick" electrodes. Caco-2 monolayers with an initial TER of more than $250 \Omega \cdot \mathrm{cm}^{2}$ were used for the subsequent experiments. The TER was measured before adding fresh DMEM or DMEM-containing yogurt to the apical surface. For cytokine stimulation, the Caco- 2 cells were incubated at $37^{\circ} \mathrm{C}$ in DMEM or DMEM-containing yogurt for $3 \mathrm{~h}$ before basolateral addition of $10 \mathrm{ng} / \mathrm{mL}$ of IL-1 $\beta$ (R\&D Systems, Minneapolis, MN). The TER measurements were taken after 24 and 36 h IL-1 $\beta$ treatment.

\section{Paracellular Permeability Assay}

Paracellular permeability was determined by the flux of fluorescein isothiocyanate-dextran (FITC-dextran; $4 \mathrm{kDa}$; Sigma, St. Louis, MO) through differentiated Caco-2 monolayers as previously described with minor modifications (Hubatsch et al., 2007). After 36 h stimulation with IL-1 $\beta$, apical medium in each insert was replaced with $200 \mu \mathrm{L}$ of DMEM supplemented with $2 \mathrm{mg} / \mathrm{mL}$ of FITC-dextran. Aliquots were taken from the basolateral side every $30 \mathrm{~min}$. The fluorescence intensity of these basolateral aliquots was measured immediately after sampling using excitation/emission wavelengths of $485 / 530 \mathrm{~nm}$ in Tecan infinite M200 microplate reader (Tecan, Männedorf, Switzerland). The concentration of FITC-dextran was calculated on the basis of a standard curve. The apparent permeability coefficient, $P_{\text {app }}(\mathrm{cm} / \mathrm{s})$, was determined according to the following equation: 


$$
P_{\text {app }}=\frac{\mathrm{d} Q}{\mathrm{~d} t} \frac{1}{A \times C_{0}}
$$

where $\mathrm{d} Q / \mathrm{d} t$ is the amount of FITC transported per second $(\mathrm{ng} / \mathrm{s}), A$ is the surface area of the filter $\left(\mathrm{cm}^{2}\right)$, and $C_{0}$ is the initial FITC concentration in the apical side $(\mathrm{ng} / \mathrm{mL})$.

\section{ELISA Assay for IL-8 Detection}

After 36 h stimulation with IL-1 $\beta$, DMEM collected from both apical and basolateral side was used for quantification of IL- 8 by IL-8 Human ELISA Kit (Life Technologies, Carlsbad, CA). All assays were performed in triplicate according to the manufacturer's instructions.

\section{RNA Extraction and RT-qPCR}

Total RNA from the Caco-2 monolayers was isolated using TRIzol reagent (Invitrogen) after $36 \mathrm{~h}$ stimulation with IL-1 $\beta$ and purified using DNA-free DNA Removal Kit (Invitrogen). The quantity and quality of RNA was determined using Qubit RNA HS Assay Kit (Life Technologies) and Agilent 2100 Bioanalyzer (Agilent Technologies, Santa Clara, CA), respectively. Purified RNA $(1 \mu \mathrm{g})$ was reverse transcribed to cDNA using the RevertAid First Strand cDNA Synthesis Kit (Thermo Scientific), following the manufacturer's protocol. The RT-qPCR was performed using SsoFast Eva Green Supermix (Bio-Rad, Hercules, CA) on a LightCycler 480 real-time thermocycler (Roche Diagnostics, Meylan, France). The primers used for RT-qPCR are listed in Supplemental Table S2 (https://doi.org/10 .3168/jds.2018-15226). Primer specificity was assessed by examination of the melting curve at the end of amplification. All reactions were performed in triplicate. Data were analyzed using the $2^{-\Delta \Delta \mathrm{Ct}}$ method corrected for primer efficiencies using the untreated group mean as the reference condition (Schmittgen and Livak, 2008; Putt et al., 2017). The housekeeping gene GAPDH was used for transcript normalization.

\section{Cytotoxicity Assay}

After treatment of Caco-2 cell monolayers with IL$1 \beta, 100 \mu \mathrm{L}$ of medium from the apical chamber was collected and lactate dehydrogenase (LDH) leakage was determined using a Pierce LDH Cytotoxicity Assay Kit (Thermo Scientific). All assays were performed in triplicate according to the manufacturer's instructions. Cell lysates of the Caco-2 cell monolayers were used as the positive control. Cytotoxicity data were expressed as percent of the positive control (100\% of released LDH activity).

\section{Statistical Analysis}

Data were analyzed using GraphPad Prism 6 software for Windows (GraphPad Software Inc., La Jolla, CA). All data are reported as mean \pm standard deviation and analyzed by 1-way ANOVA with Tukey's post hoc test to calculate the $P$-value. Bars with different letters are statistically significant $(P<0.05)$.

\section{RESULTS}

\section{Prevention of the IL-1 $\beta$-Induced TER Reduction by Yogurt}

To investigate the effects of milk on intestinal barrier, an in vitro Caco-2 monolayer model was employed in this study. In Caco-2 cells, cytotoxicity was $2.57 \pm$ $0.61 \%$ for IL- $1 \beta, 1.44 \pm 0.76 \%$ for nonfat yogurt, and $1.68 \pm 1.06 \%$ for low-fat yogurt, respectively. Thus, treatments with IL-1 $\beta$ or DMEM containing $25 \%$ vol/ vol yogurt for $36 \mathrm{~h}$ were not lethal in Caco-2 monolayers, as less than $5 \%$ of $\mathrm{LDH}$ activity was released in comparison to the positive control. When the Caco-2 monolayer was treated apically with DMEM supplemented with $25 \% \mathrm{vol} / \mathrm{vol}$ nonfat or low-fat yogurt, the TER was not decreased even after $36 \mathrm{~h}$ of incubation, further indicating that $25 \% \mathrm{vol} / \mathrm{vol}$ yogurt samples did not have any cytotoxic effects on the Caco-2 monolayer (Figure 1). Therefore, 25\% vol/vol yogurt in DMEM was chosen for the subsequent experiments.

In this study, the TER was significantly decreased to $75.07 \pm 3.40 \%$ after $36 \mathrm{~h}$ of IL- $1 \beta$ stimulation (Figure $2, P<0.01)$. However, the TER reduction was prevented when the monolayers were pretreated with either nonfat or low-fat yogurt. The average TER reduction was $5.41 \%$ in nonfat yogurt treated cells and $6.85 \%$ in low-fat yogurt treated cells, respectively. No significant difference was observed between nonfat and low-fat yogurt treatment (Figure 2, $P=0.4806$ ).

\section{Reduction of Paracellular Permeability by Low-Fat Yogurt}

As an indicator of epithelial permeability to ionic solutes, TER is a nonspecific marker of intestinal barrier function. The TER is an instantaneous measurement of the ion channels in the barrier, whereas the intestinal barrier is dynamic (Anderson and Van Itallie, 2009). Thus, paracellular permeability to large, uncharged macromolecules (over $4 \AA$ ) over 30 min was 
$\square$ NT

$25 \%$ non-fat yogurt

$\square 25 \%$ low-fat yogurt

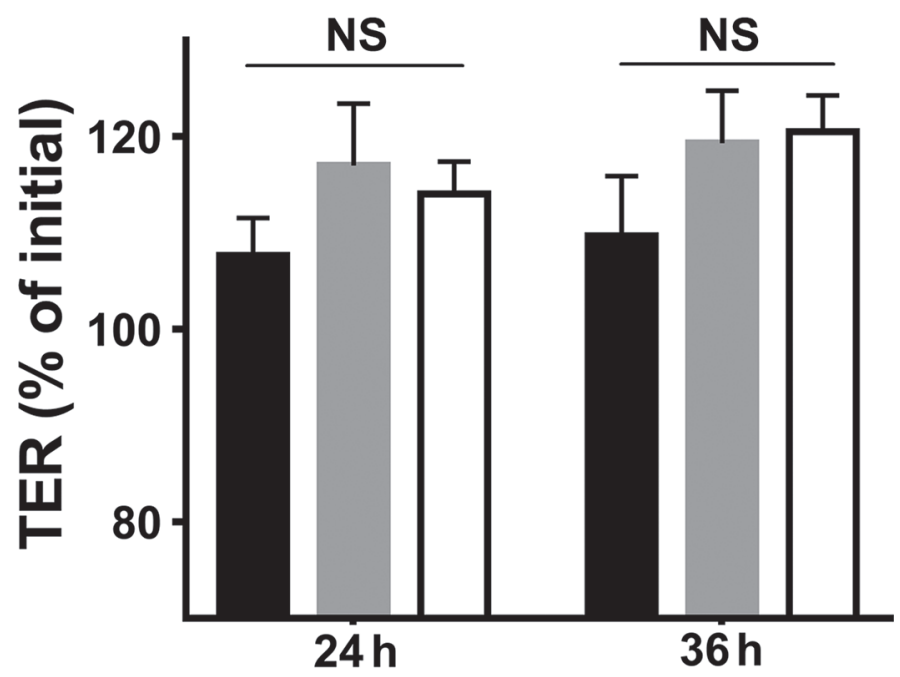

Figure 1. The effects of Dulbecco's modified Eagle medium (DMEM) containing $25 \% \mathrm{vol} / \mathrm{vol}$ yogurt on Caco-2 transepithelial electrical resistance (TER). Caco-2 monolayers were either not treated (NT; black bars) or apically treated with DMEM containing 25\% vol/ vol nonfat or low-fat yogurt. The TER measurements were carried out after 24 and $36 \mathrm{~h}$ of incubation. Data are reported as mean $\pm \mathrm{SD}$. NS $=$ no significant difference $(\mathrm{n}=3, \mathrm{P}>0.05)$.

measured using FITC-dextran $(4.4 \mathrm{kDa}, 14 \AA)$. In our Caco-2 model, IL-1 $\beta$ increased the permeability of Caco-2 monolayer to FITC-dextran (Figure 3). The permeability coefficient $\left(P_{\text {app }}\right)$ of inflamed Caco-2 cells was $28.95 \pm 0.44 \times 10^{-5} \mathrm{~cm} / \mathrm{s}$, which was significantly higher than that of the nontreated cells. Notably, the $P_{\text {app }}$ of low-fat yogurt treated cells was $19.53 \pm 1.46 \times$ $10^{-5} \mathrm{~cm} / \mathrm{s}$, indicating that low-fat yogurt reduced the cytokines mediated increased permeability significantly $(P<0.01)$. However, nonfat yogurt did not affect the paracellular permeability of inflamed cells. The $P_{\text {app }}$ of nonfat yogurt cells was average $26.26 \pm 2.27 \times 10^{-5}$ $\mathrm{cm} / \mathrm{s}$, which was comparable to that of the inflamed cells $(P>0.05)$.

\section{Repression of the IL-8 Production by Low-Fat Yogurt}

To further determine the anti-inflammatory effects of yogurt, the production of IL-8, which is an indicator of inflammation in epithelial cells (Jobin et al., 1999; Donato et al., 2010), was detected by ELISA assay. After IL-1 $\beta$ stimulation, the concentration of IL- 8 in basal medium in inflamed cells was significantly increased to $407.20 \pm 50.05 \mathrm{pg} / \mathrm{mL}$, which was 8.74 -fold higher than that of nontreated cells (Figure $4, P<$
$0.01)$. It is worth to note that pre-treatment with lowfat yogurt prevented the IL- $1 \beta$ induced IL- 8 production significantly $(P<0.01)$. The concentration of IL-8 in low-fat yogurt treated cells was decreased to $252.40 \pm$ $27.24 \mathrm{pg} / \mathrm{mL}$, indicating the anti-inflammatory roles of low-fat yogurt. A trend was observed for decreased production of IL-8 in inflamed Caco- 2 monolayers in response to nonfat yogurt, but the difference did not reach significance (Figure 4).

\section{Down-Regulation of MLCK Gene by Low-Fat Yogurt}

According to previous studies, the major effector responsible for IL-1 $\beta$ induced intestinal barrier disruption is myosin light chain kinase (MLCK). The expression of epithelial MLCK is demonstrated to be increased by IL-1 $\beta$ via $N F-\kappa B$ signaling pathway. In this study, we found that the $M L C K \mathrm{mRNA}$ levels were increased significantly in Caco-2 cells after IL- $1 \beta$ stimulation (Figure $5, P<0.05)$. No significant difference was observed between inflamed cells and nonfat yogurt treated cells on the expression of $M L C K$. However, the transcript level of $M L C K$ mRNA in low-fat yogurt treated cells was significantly decreased (Figure $5, P<0.05$ ). These results indicated that low-fat yogurt prevented the IL$1 \beta$-induced intestinal barrier disruption by inhibiting the upregulation of $M L C K$ in Caco-2 cells.

\section{Transcription of Some Tight Junction Genes in Response to IL-1 $\beta$ or Yogurt}

In addition to preventing tight junction reorganization and epithelial barrier disruption, yogurts also altered the expression of some tight junction genes in Caco-2 cells (Putt et al., 2017). The transcript level of occludin $(O C L N)$, claudin-3 (CLDN3), and tight junction protein ZO-1 (TJP1) mRNA in Caco-2 cells was determined by RT-qPCR. The mRNA levels of $O C L N$ were not significantly affected by either IL-1 $\beta$ or yogurt. The CLDN3 gene was 3.6-fold downregulated in Caco-2 cells pre-treated with IL-1 $\beta$, compared with untreated control (Figure 6, $P<0.05$ ). Both nonfat yogurt and low-fat yogurt prevented the downregulation of $C L D N 3$

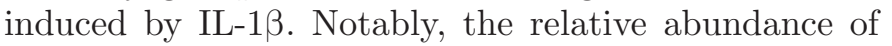
TJP1 transcripts was significantly increased in Caco-2 cells exposed to low-fat yogurt. However, no significant difference was observed on the transcript level of TJP1 between the inflamed cells and nonfat yogurt treated cells.

\section{DISCUSSION}

The intestinal epithelium provides a physical barrier that protects the host tissues from luminal contents. 


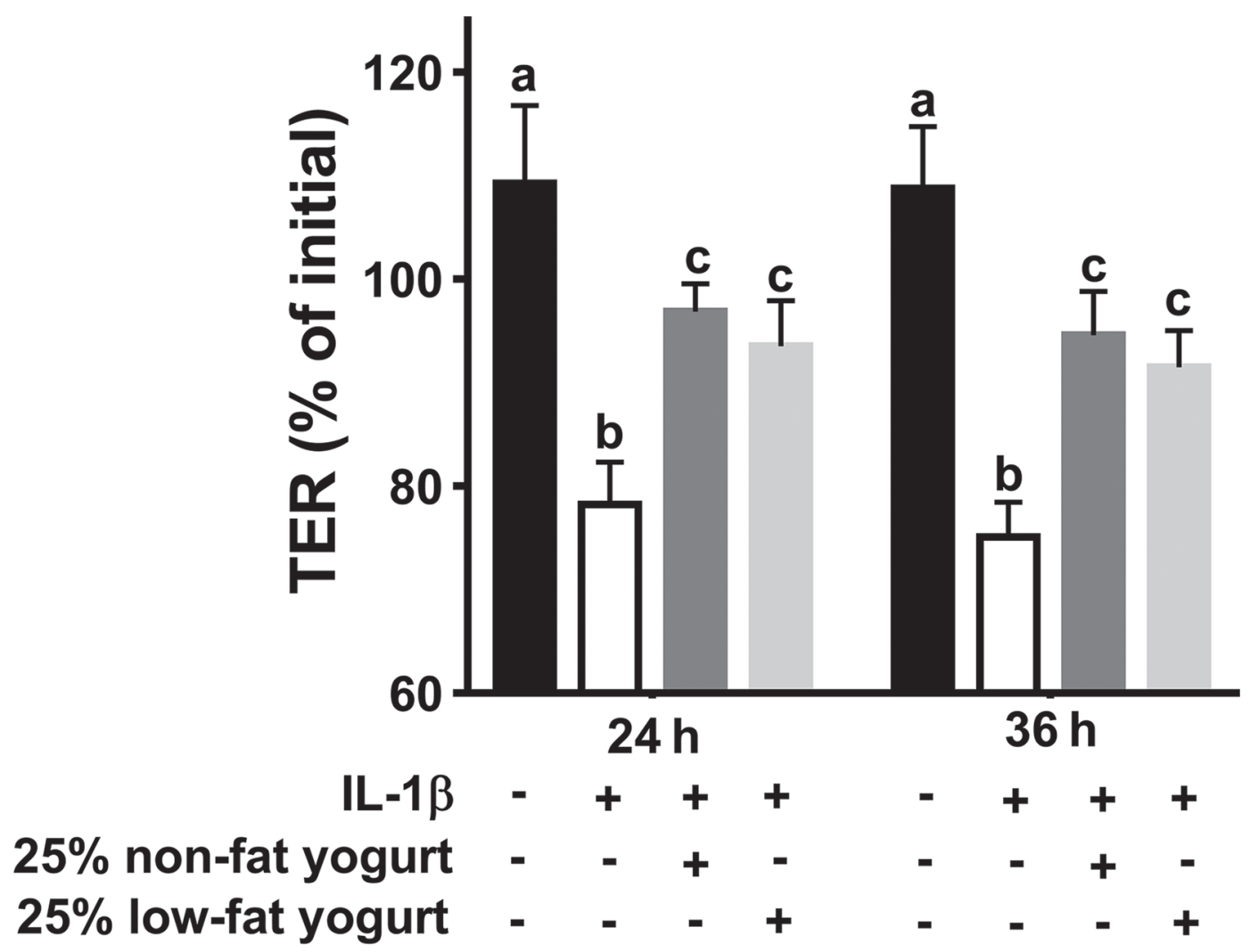

Figure 2. Dulbecco's modified Eagle medium (DMEM) containing 25\% (vol/vol) yogurt prevented the reduction in transepithelial electrical resistance (TER) caused by pro-inflammatory cytokine IL-1 $\beta$. Caco-2 monolayers were either untreated (black bars) or basally stimulated with $10 \mathrm{ng} / \mathrm{mL}$ of IL-1 $\beta$ (white bars). Fresh DMEM (with or without $25 \%$ vol/vol nonfat or low-fat yogurt) was added $3 \mathrm{~h}$ before IL-1 $\beta$ exposure. The TER measurements were carried out at different time points $24 \mathrm{~h}$ after IL-13 addition. Data are reported as mean \pm SD and analyzed by 1-way ANOVA with Tukey's post hoc test. Bars with different letters are significantly different $(\mathrm{n}=6, P<0.05)$.

The intestinal barrier dysfunction results in an increase in gut permeability, which is associated with inflammation and gut diseases (Schulzke et al., 2009). In this study, Caco-2 monolayer was employed to simulate the intestinal epithelium, and pro-inflammatory cytokine IL-1 $\beta$ was applied to induce intestinal barrier dysfunction. We found that low-fat bovine yogurt prevented both the TER reduction and FITC-dextran transloca-

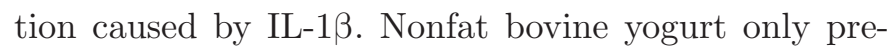
vented the TER reduction in Caco-2 cells. Moreover, low-fat yogurt prevented the IL-8 production significantly in inflamed Caco-2 cells, whereas nonfat yogurt did not affect IL-8 production or repressed IL-8 production with less efficiency. Hence, our results indicate that low-fat bovine yogurt mitigates intestinal inflammation by maintaining the epithelial barrier integrity beyond nonfat yogurt.

Dairy products as well as yogurt made from bovine milk were previously reported to improve the intestinal barrier and have anti-inflammatory effects in the GI tract (Baldi et al., 2005; Ozawa et al., 2009; Yasumatsu and Tanabe, 2010; Hering et al., 2011; Putt et al.,
2017). However, comparative studies on different types of yogurt are lacking. Considering the differences in composition between low-fat and nonfat yogurt made from bovine milk, it is possible that fatty acid content and composition might serve important roles in maintaining the gut barrier. After fermentation, the fat content of low-fat and nonfat yogurt was $1.47 \pm 0.12$ $\mathrm{g}$ and $0.26 \pm 0.21 \mathrm{~g}$ per $100 \mathrm{~g}$ of sample, respectively (Supplemental Table S3; https://doi.org/10.3168/jds .2018-15226). Some fatty acids in dairy products have been reported to be beneficial to intestinal barrier function, such as short-chain fatty acids, linoleic acids, and cis-9,trans-11-CLA (Collomb et al., 2004; Månsson, 2008; Willemsen et al., 2008). Linoleic acid and cis-9,trans-11-CLA were found to increase TER during prolonged incubation with the Caco-2 monolayer (Roche et al., 2001). Moreover, cis-9,trans-11-CLA was suggested to exert anti-inflammatory effects in human epithelial cells (Jaudszus et al., 2005). In addition, lactic acid bacteria such as L. bulgaricus and S. thermophilus can produce cis-9,trans-11-CLA from free linoleic acid (Van Nieuwenhove et al., 2007; Yang 


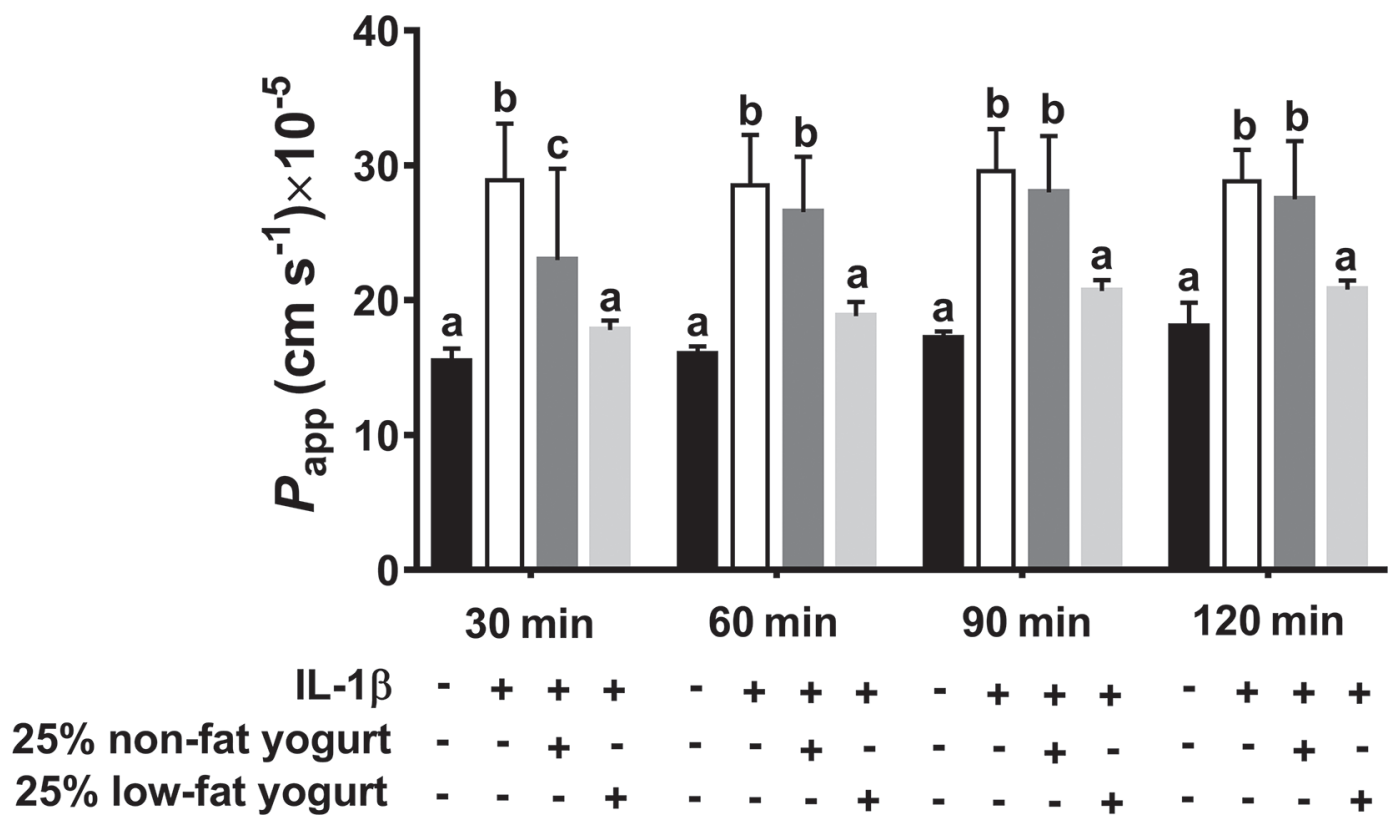

Figure 3. The permeability coefficient $\left(P_{\text {app }}\right.$, unit: $\left.\mathrm{cm} \cdot \mathrm{s}^{-1}\right)$ of $4 \mathrm{kDa}$ of fluorescein isothiocyanate-dextran was measured at different time points after IL-1 $\beta$ exposure for $36 \mathrm{~h}$. Data are reported as mean \pm SD and analyzed by 1-way ANOVA with Tukey's post hoc test. Bars with different letters are significantly different $(\mathrm{n}=6, P<0.05)$.

et al., 2014). But most of these fatty acids could be removed during the preparation of nonfat bovine milk. Thus, although the amounts of these strains were comparable between low-fat and nonfat yogurt, there were no linoleic acid and cis-9,trans-11-CLA detected in nonfat yogurt (Supplemental Table S3; https://doi .org/10.3168/jds.2018-15226). This maybe explains why nonfat yogurt pretreatment showed less protection on intestinal epithelial barrier integrity, but additional studies are needed to confirm this hypothesis.

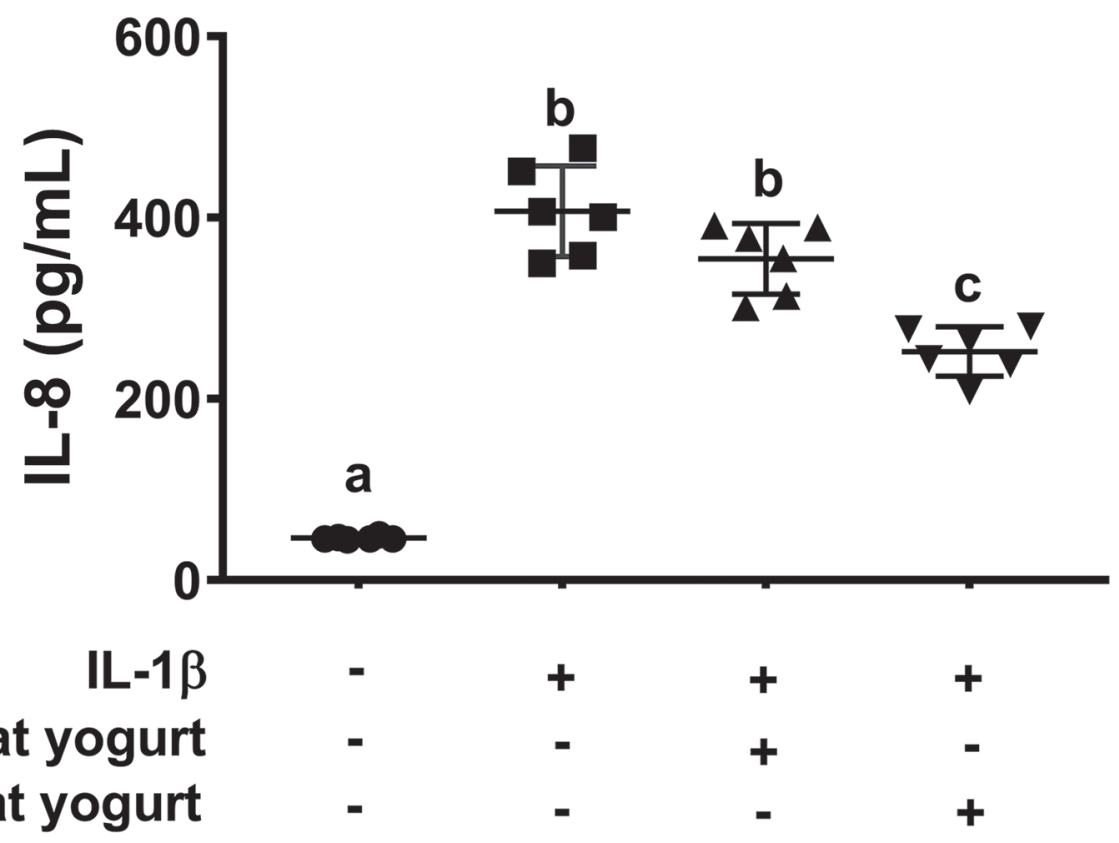

Figure 4. Low-fat yogurt alleviates the effects of IL-1 $\beta$ on IL- 8 production in Caco- 2 cells. Basolateral concentrations of IL- 8 were measured $36 \mathrm{~h}$ after cytokine induction. Data are reported as mean $\pm \mathrm{SD}(\mathrm{n}=6)$ and analyzed by 1-way ANOVA with Tukey's post hoc test. Bars with different letters are significantly different $(P<0.05)$. 


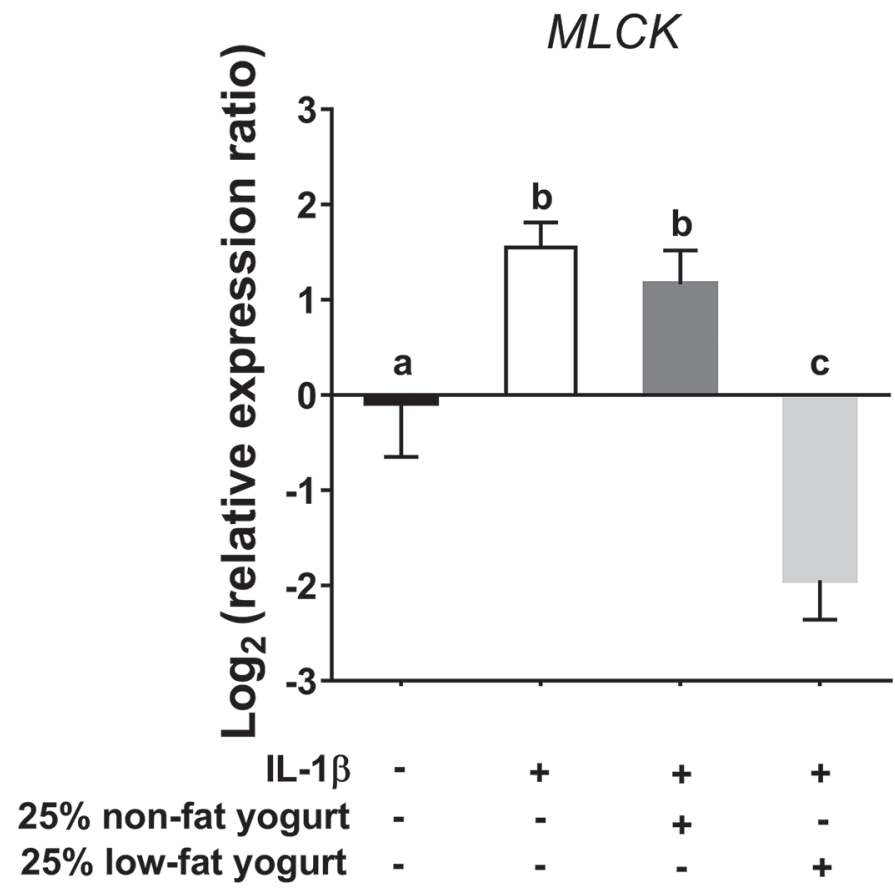

Figure 5. The expression of $M L C K$ was downregulated by low-fat yogurt treatment. Data are reported as mean $\pm \mathrm{SD}(\mathrm{n}=6)$ and analyzed by 1-way ANOVA with Tukey's post hoc test. Bars with different letters are significantly different $(P<0.05)$.
Myosin light chain kinase plays a central role in IL-1 $\beta$ modulation of intestinal epithelial barrier (Al-Sadi et al., 2011). Previous studies have shown that the IL-1 $\beta$ induced increase in intestinal epithelial permeability was mediated by an increase in $M L C K$ mRNA transcription and protein synthesis (Al-Sadi et al., 2010). The activation of the NF- $\kappa$ B signaling pathway plays a critical role in altering transcription of genes including $M L C K$ and $I L-8$ to contribute to the inflammatory process and disruption of the epithelial barrier (Ye et al., 2006). Myosin light chain kinase phosphorylates myosin II regulatory light chain to trigger contractions in the actomyosin ring, leading to tight junction endocytosis and increased permeability of epithelium (Cunningham and Turner, 2012). In this study, we observed that IL-1 $\beta$ stimulation caused an increased transcription of $M L C K$ in Caco-2 cells. However, the transcription of $M L C K$ was downregulated by low-fat yogurt pre-treatment, implying that a dampening of the NF- $\kappa \mathrm{B}$ signaling pathway. This was further confirmed by detecting the protein level of I $\kappa \mathrm{B} \alpha$ by Western blot (Supplemental Figure S1; https://doi.org/10.3168/jds.2018-15226). Low-fat yogurt could inhabit the degradation of $\mathrm{I} \kappa \mathrm{B} \alpha$ in Caco2 cells to dampen the NF- $\kappa \mathrm{B}$ activation induced by IL-1ß. According to previous studies, food components

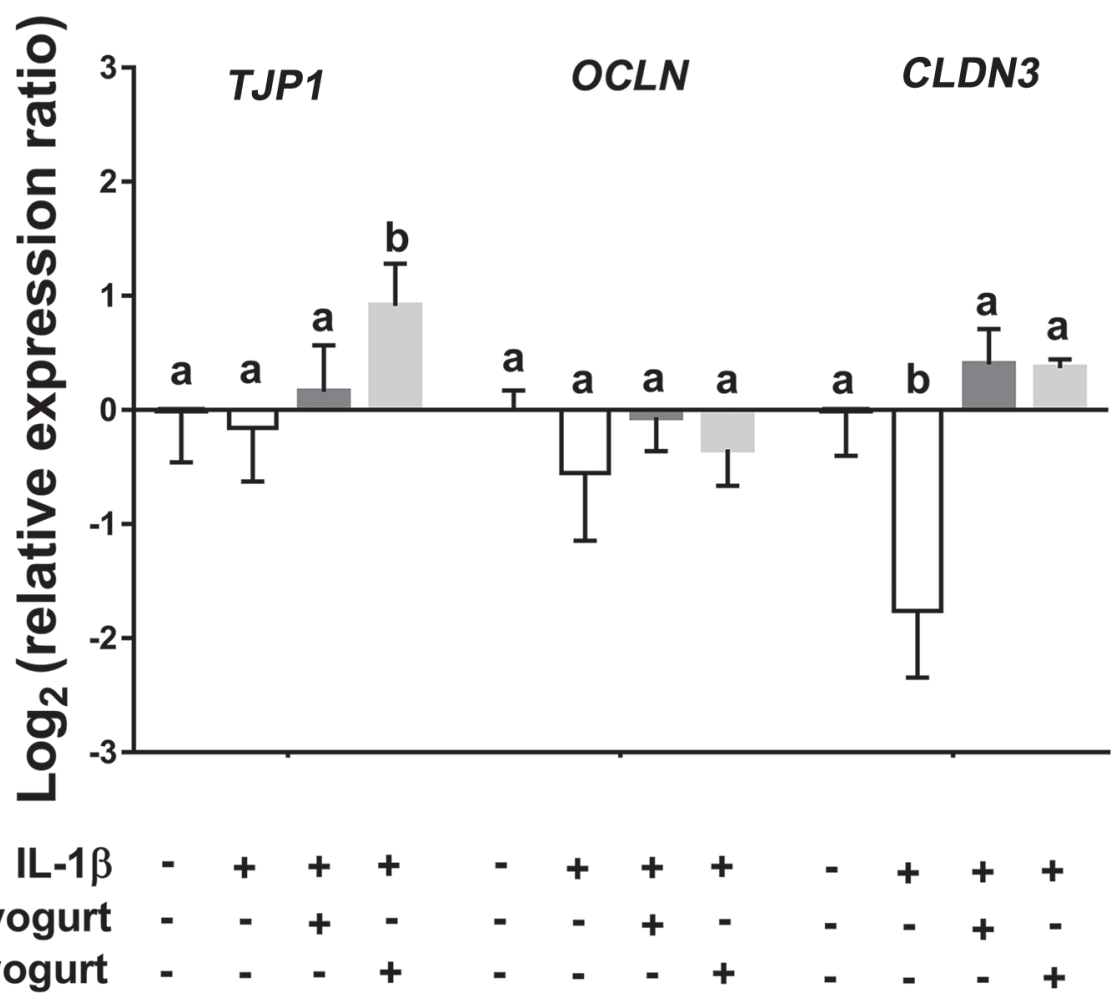

Figure 6. The expression of TJP1, OCLN, and CLDN3 gene in Caco-2 monolayer after IL-1 $\beta$ stimulation was determined by quantitative reverse-transcription PCR. Data are reported as mean $\pm \mathrm{SD}(\mathrm{n}=6)$ and analyzed by 1-way ANOVA with Tukey's post hoc test. Bars with different letters are significantly different $(P<0.05)$. 
and probiotics are able to alleviate the inflammation by blocking the NF- $\kappa \mathrm{B}$ signaling pathway (Gilmore and Herscovitch, 2006; Prabhala, 2013). A $\beta$-casein-derived peptide was identified to having an anti-inflammatory effect by inhibiting NF- $\kappa$ B signaling pathway in vitro (Malinowski et al., 2014). Secretions of Bifidobacterium infantis and $L$. acidophilus protected the intestinal barrier against IL-1 $\beta$ by inhibiting NF- $\kappa \mathrm{B}$ activation in human intestinal necrotizing enterocolitis models (Guo et al., 2015).

In addition, probiotics and food components have been reported to prevent cytokine-induced gut barrier disruption by altering the expression of tight junction genes (Bron et al., 2017). In our Caco-2 model, the transcripts of $C L D N 3$ were decreased in response to IL-1 $\beta$, whereas the transcription of TJP1 and OCLN was not affected by IL-1 $\beta$. Haines et al. (2016) also found that IL-1 $\beta$ caused epithelial barrier dysfunction via downregulating the expression of claudin-3. Both low-fat and nonfat yogurt were able to restore the transcription of $C L D N 3$ in inflamed cells. Notably, the mRNA level of TJP1 in low-fat yogurt pre-treated cells was significantly higher than that of other groups. Low-fat yogurt was reported to increase the expression of TJP1 and inhibit the intestinal barrier dysfunction in Caco-2 cells (Putt et al., 2017). By comparison, in our cell model, we found that nonfat yogurt was unable to increase the transcription of TJP1. However, little is known about the inhibition of NF- $\kappa \mathrm{B}$ signaling pathway or modulation of tight junction expression by low-fat yogurt, because the effector molecule and receptor are still unclear. These findings that low-fat yogurt enhances intestinal barrier and attenuates inflammation in epithelial cells will support the identification of beneficial effector molecules in yogurt and the reconsideration of dairy fat in managing intestinal inflammatory disorders.

\section{ACKNOWLEDGMENTS}

This work was supported by National Key Research and Development Program of China (2018YFD0401200, 2016YFD0400802), Joint Program of Beijing Natural Science Foundation and Beijing Municipal Education Commission, National Natural Science Foundation of China (31401669), Beijing Natural Science Foundation (5154027), and Support Project of High-level Teachers in Beijing Municipal Universities (IDHT20180506).

\section{REFERENCES}

Adolfsson, O., S. N. Meydani, and R. M. Russell. 2004. Yogurt and gut function. Am. J. Clin. Nutr. 80:245-256.

Al-Sadi, R., D. Ye, H. M. Said, and T. Y. Ma. 2010. IL-1beta-induced increase in intestinal epithelial tight junction permeability is me- diated by MEKK-1 activation of canonical NF-kappaB pathway. Am. J. Pathol. 177:2310-2322.

Al-Sadi, R., D. Ye, H. M. Said, and T. Y. Ma. 2011. Cellular and molecular mechanism of interleukin-1 $\beta$ modulation of Caco-2 intestinal epithelial tight junction barrier. J. Cell. Mol. Med. 15:970-982.

Anderson, J. M., and C. M. Van Itallie. 2009. Physiology and function of the tight junction. Cold Spring Harbor Perspect. Biol. 1:a002584.

Astrup, A. 2014. Yogurt and dairy product consumption to prevent cardiometabolic diseases: Epidemiologic and experimental studies. Am. J. Clin. Nutr. 99:1235S-1242S.

Baldi, A., P. Ioannis, P. Chiara, F. Eleonora, C. Roubini, and D. Vittorio. 2005. Biological effects of milk proteins and their peptides with emphasis on those related to the gastrointestinal ecosystem. J. Dairy Res. 72:66-72.

Bron, P. A., M. Kleerebezem, R. J. Brummer, P. D. Cani, A. Mercenier, T. T. Macdonald, C. L. Garciaródenas, and J. M. Wells. 2017. Can probiotics modulate human disease by impacting intestinal barrier function? Br. J. Nutr. 117:93-107.

Chaves, S., G. Perdigon, and M. L. A. De. 2011. Yoghurt consumption regulates the immune cells implicated in acute intestinal inflammation and prevents the recurrence of the inflammatory process in a mouse model. J. Food Prot. 74:801-811.

Chichlowski, M., and L. P. Hale. 2008. Bacterial-mucosal interactions in inflammatory bowel disease-An alliance gone bad. Am. J. Physiol. Gastrointest. Liver Physiol. 295:G1139-G1149.

Citi, S. 2018. Intestinal barriers protect against disease. Science 359:1097-1098.

Collomb, M., R. Sieber, and U. Bütikofer. 2004. CLA isomers in milk fat from cows fed diets with high levels of unsaturated fatty acids. Lipids 39:355-364.

Cunningham, K. E., and J. R. Turner. 2012. Myosin light chain kinase: Pulling the strings of epithelial tight junction function. Ann. N. Y. Acad. Sci. 1258:34-42

Donato, K. A., M. G. Gareau, Y. J. J. Wang, and P. M. Sherman. 2010. Lactobacillus rhamnosus GG attenuates interferon- $\gamma$ and tumour necrosis factor- $\alpha$-induced barrier dysfunction and proinflammatory signalling. Microbiology 156:3288-3297.

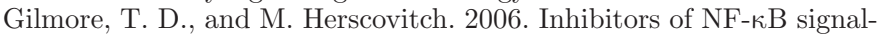
ing: 785 and counting. Oncogene 25:6887-6899.

Gobbato, N., M. Rachid, and G. Perdigón. 2008. Anti-inflammatory effect of yoghurt in an experimental inflammatory bowel disease in mouse. J. Dairy Res. 75:497-504.

Guo, S., Y. Guo, A. Ergun, L. Lu, W. A. Walker, and K. Ganguli. 2015. Secreted metabolites of Bifidobacterium infantis and Lactobacillus acidophilus protect immature human enterocytes from IL$1 \beta$-induced inflammation: A transcription profiling analysis. PLoS One 10:e0124549.

Haines, R. J., R. S. B. Jr, L. Chen, R. A. Eitnier, and M. H. Wu. 2016. Interleukin-1 $\beta$ mediates $\beta$-catenin-driven downregulation of claudin-3 and barrier dysfunction in caco2 cells. Dig. Dis. Sci. 61:2252-2261.

Hering, N. A., S. Andres, A. Fromm, E. A. van Tol, M. Amasheh, J. Mankertz, M. Fromm, and J. D. Schulzke. 2011. Transforming growth factor- $\beta$, a whey protein component, strengthens the intestinal barrier by upregulating claudin-4 in HT-29/B6 cells. J. Nutr. 141:783-789.

Horwitz, W. 1980. Official Methods of Analysis. AOAC, Washington, DC.

Horwitz, W. 2000. AOAC Official Method 905.02 Fat in milk. Official Methods of Analysis of AOAC International.

Hubatsch, I., E. G. E. Ragnarsson, and P. Artursson. 2007. Determination of drug permeability and prediction of drug absorption in Caco-2 monolayers. Nat. Protoc. 2:2111-2119.

Jaudszus, A., M. Foerster, C. Kroegel, I. Wolf, and G. Jahreis. 2005. Cis-9,trans-11-CLA exerts anti-inflammatory effects in human bronchial epithelial cells and eosinophils: Comparison to trans10,cis-12-CLA and to linoleic acid. Biochim. Biophys. Acta 1737:111-118.

Jobin, C., L. Holt, C. A. Bradham, K. Streetz, D. A. Brenner, and R. B. Sartor. 1999. TNF receptor-associated factor-2 is involved 
in both IL-1 $\beta$ and TNF- $\alpha$ signaling cascades leading to NF- $\kappa B$ activation and IL-8 expression in human intestinal epithelial cells. J. Immunol. 162:4447-4454.

Knight, P., B. J. Campbell, and J. M. Rhodes. 2008. Host-bacteria interaction in inflammatory bowel disease. Br. Med. Bull. 88:95-113.

Luissint, A. C., C. A. Parkos, and A. Nusrat. 2016. Inflammation and the intestinal barrier: Leukocyte-epithelial cell interactions, cell junction remodeling, and mucosal repair. Gastroenterology 151:616-632.

Luna, P., M. Juárez, and D. L. F. Ma. 2005. Validation of a rapid milk fat separation method to determine the fatty acid profile by gas chromatography. J. Dairy Sci. 88:3377-3381.

Malinowski, J., M. Klempt, I. Clawinrädecker, P. C. Lorenzen, and H. Meisel. 2014. Identification of a NFkB inhibitory peptide from tryptic $\beta$-casein hydrolysate. Food Chem. 165:129-133.

Månsson, H. L. 2008. Fatty acids in bovine milk fat. Food Nutr. Res. 52. https://doi.org/10.3402/fnr.v52i0.1821.

Meydani, S. N., and W. K. Ha. 2000. Immunologic effects of yogurt. Am. J. Clin. Nutr. 71:861-872.

Ohland, C. L., and W. K. MacNaughton. 2010. Probiotic bacteria and intestinal epithelial barrier function. Am. J. Physiol. Gastrointest. Liver Physiol. 298:G807-G819.

Ozawa, T., M. Miyata, M. Nishimura, T. Ando, Y. Ouyang, T. Ohba N. Shimokawa, Y. Ohnuma, R. Katoh, and H. Ogawa. 2009. Transforming growth factor-beta activity in commercially available pasteurized cow milk provides protection against inflammation in mice. J. Nutr. 139:69-75.

Pei, R., D. M. DiMarco, K. K. Putt, D. A. Martin, C. Chitchumroonchokchai, R. S. Bruno, and B. W. Bolling. 2018. Premeal low-fat yogurt consumption reduces postprandial inflammation and markers of endotoxin exposure in healthy premenopausal women in a randomized controlled trial. J. Nutr. 148:910-916.

Peterson, L. W., and D. Artis. 2014. Intestinal epithelial cells: Regulators of barrier function and immune homeostasis. Nat. Rev. Immunol. 14:141.

Prabhala, R. H. 2013. Chapter 21-Anti-inflammatory natural foods. Pages 279-303 in Bioactive Food as Dietary Interventions for Arthritis and Related Inflammatory Diseases. R. R. Watson and V. R. Preedy, ed. Academic Press, San Diego, CA.

Putt, K. K., R. Pei, H. M. White, and B. W. Bolling. 2017. Yogurt inhibits intestinal barrier dysfunction in Caco-2 cells by increasing tight junctions. Food Funct. 8:406-414.

Roche, H., A. Terres, I. Black, M. Gibney, and D. Kelleher. 2001. Fatty acids and epithelial permeability: Effect of conjugated linoleic acid in Caco-2 cells. Gut 48:797-802.

Schmittgen, T. D., and K. J. Livak. 2008. Analyzing real-time PCR data by the comparative CT method. Nat. Protoc. 3:1101.
Schulzke, J. D., S. Ploeger, M. Amasheh, A. Fromm, S. Zeissig, H Troeger, J. Richter, C. Bojarski, M. Schumann, and M. Fromm, 2009. Epithelial tight junctions in intestinal inflammation. Ann. N. Y. Acad. Sci. 1165:294-300.

Southcott, E., K. L. Tooley, G. S. Howarth, G. P. Davidson, and R. N. Butler. 2008. Yoghurts containing probiotics reduce disruption of the small intestinal barrier in methotrexate-treated rats. Dig. Dis. Sci. 53:1837-1841.

Suenaert, P., V. Bulteel, L. Lemmens, M. Noman, B. Geypens, G. Van Assche, K. Geboes, J. L. Ceuppens, and P. Rutgeerts. 2002. Antitumor necrosis factor treatment restores the gut barrier in Crohn's disease. Am. J. Gastroenterol. 97:2000.

Talley, N. J., M. T. Abreu, J.-P. Achkar, C. N. Bernstein, M. C. Dubinsky, S. B. Hanauer, S. V. Kane, W. J. Sandborn, T. A. Ullman, and P. Moayyedi. 2011. An evidence-based systematic review on medical therapies for inflammatory bowel disease. Am. J. Gastroenterol. 106:S2-S5.

Trigueros, L., and E. Sendra. 2015. Fatty acid and conjugated linoleic acid (CLA) content in fermented milks as assessed by direct methylation. Lebensm. Wiss. Technol. 60:315-319.

Usui, Y., Y. Kimura, T. Satoh, N. Takemura, Y. Ouchi, H. Ohmiya, K. Kobayashi, H. Suzuki, S. Koyama, S. Hagiwara, H. Tanaka, S. Imoto, G. Eberl, Y. Asami, K. Fujimoto, and S. Uematsu. 2018. Effects of long-term intake of a yogurt fermented with Lactobacillus delbrueckii ssp. bulgaricus 2038 and Streptococcus thermophilus 1131 on mice. Int. Immunol. 30:319-331.

Van Nieuwenhove, C. P., R. Oliszewski, S. N. Gonzalez, and A. B Pérez Chaia. 2007. Conjugated linoleic acid conversion by dairy bacteria cultured in MRS broth and buffalo milk. Lett. Appl. Microbiol. 44:467-474.

Willemsen, L. E., M. A. Koetsier, M. Balvers, C. Beermann, B. Stahl, and E. A. van Tol. 2008. Polyunsaturated fatty acids support epithelial barrier integrity and reduce IL- 4 mediated permeability in vitro. Eur. J. Nutr. 47:183-191.

Xavier, R., and D. Podolsky. 2007. Unravelling the pathogenesis of inflammatory bowel disease. Nature 448:427-434.

Yang, B., H. Chen, Z. Gu, F. Tian, R. Ross, C. Stanton, Y. Chen, W. Chen, and H. Zhang. 2014. Synthesis of conjugated linoleic acid by the linoleate isomerase complex in food-derived lactobacilli. J. Appl. Microbiol. 117:430-439.

Yasumatsu, H., and S. Tanabe. 2010. The casein peptide Asn-Pro-TrpAsp-Gln enforces the intestinal tight junction partly by increasing occludin expression in Caco-2 cells. Br. J. Nutr. 104:951-956.

Ye, D., I. Ma, and T. Y. Ma. 2006. Molecular mechanism of tumor necrosis factor-alpha modulation of intestinal epithelial tight junction barrier. Am. J. Physiol-Gastr. L. 290:496-504. 